\title{
OBSERVATIONAL STUDY OF EXTREMELY LOW BIRTH WEIGHT INFANTS CARED FOR IN PRE AND POST FLUCONAZOLE PROPHYLAXIS EPOCHS AT A TERTIARY NEONATAL UNIT IN UK
}

\author{
H. Gowda, D. Booth
}

Neonatal Medicine, Norfolk and Norwich University Hospital, Norwich, UK

Background and aims: Invasive fungal infection is an important cause of mortality and morbidity in extremely low birth weight (ELBW) infants. Early diagnosis is difficult and treatment is often delayed.

We assessed the impact of intravenous fluconazole prophylaxis in ELBW $[<1000 \mathrm{~g}]$ and $<750$ grams infants on the incidence of invasive candidiasis in Neonatal Intensive Care Unit.

Methods: ELBW infants born during the pre-prophylaxis era (Jan 2004 -Dec 2006) were compared with post-prophylaxis era (Aug 2007 -July 2010). Infants born during prophylaxis era received fluconazole prophylaxis for 6 weeks or as long as they had intravenous access. Demographic and clinical data were collected. The two groups were compared for baseline demographics, risk factors for candidiasis and the incidence of invasive candidiasis.

Results: 6 of 121 ELBW infants (4.9\%) developed invasive candidiasis during pre-prophylaxis era compared to 2 of $169(1.18 \%)$ during post-prophylaxis era. There was no adverse events or the emergence of fluconazole resistant Candida sp. with fluconazole prophylaxis.

\begin{tabular}{|l|l|l|l|}
\hline & $\begin{array}{l}2004-06 \text { Pre-prophylaxis } \\
\text { epoch }\end{array}$ & $\begin{array}{l}2007-10 \text { Prophylaxis } \\
\text { epoch }\end{array}$ & Risk ratio \\
\hline ELBW $<1000 \mathrm{~g}$ & $4.9 \%(6 / 121)$ & $1.18 \%(2 / 169)$ & 4.2 \\
\hline$<750 \mathrm{~g}$ & $11.3 \%(6 / 53)$ & $1.13 \%(1 / 88)$ & 9.9 \\
\hline
\end{tabular}

[Before \& after antifungal prophylaxis - comparison]

Conclusions: In post-fluconazole epoch there is $67 \%$ and $83 \%$ reduction in fungal sepsis in ELBW and < $750 \mathrm{~g}$ infants respectively. There is 4 times increased risk of invasive candidiasis in ELBW and 10 times in $<$ $750 \mathrm{~g}$ babies if fluconazole prophylaxis not given.

This study suggests that targeted Fluconazole prophylaxis regimen for ELBW infants is effective in significantly reducing invasive candidiasis. 